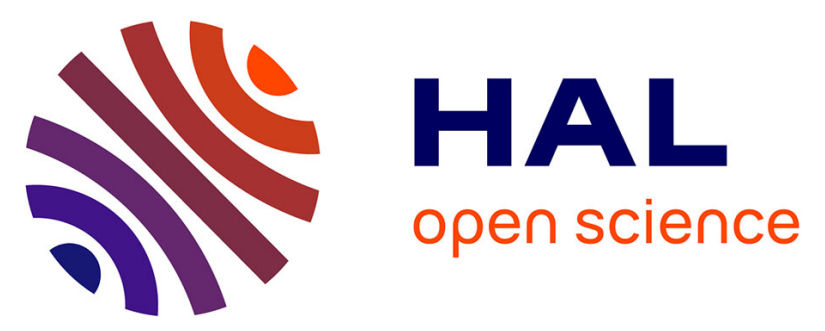

\title{
Transformation Cycle of Magnetosomes in Human Stem Cells: From Degradation to Biosynthesis of Magnetic Nanoparticles Anew
}

Alberto Curcio, Aurore van de Walle, Aida Serrano, Sandra Prévéral, Christine Péchoux, David Pignol, Nicolas Menguy, Christopher T. Lefèvre, Ana Espinosa, Claire Wilhelm

\section{To cite this version:}

Alberto Curcio, Aurore van de Walle, Aida Serrano, Sandra Prévéral, Christine Péchoux, et al.. Transformation Cycle of Magnetosomes in Human Stem Cells: From Degradation to Biosynthesis of Magnetic Nanoparticles Anew. ACS Nano, 2020, 14 (2), pp.1406-1417. 10.1021/acsnano.9b08061 . hal-02532778

\section{HAL Id: hal-02532778 \\ https://hal.inrae.fr/hal-02532778}

Submitted on 13 Nov 2020

HAL is a multi-disciplinary open access archive for the deposit and dissemination of scientific research documents, whether they are published or not. The documents may come from teaching and research institutions in France or abroad, or from public or private research centers.
L'archive ouverte pluridisciplinaire HAL, est destinée au dépôt et à la diffusion de documents scientifiques de niveau recherche, publiés ou non, émanant des établissements d'enseignement et de recherche français ou étrangers, des laboratoires publics ou privés.

\section{(c)(1)}

Distributed under a Creative Commons Attribution| 4.0 International License 


\section{Transformation Cycle of Magnetosomes in Human Stem Cells: from Degradation to Biosynthesis of Magnetic Nanoparticles Anew}

Alberto Curcio, ${ }^{*^{\dagger}}$ Aurore Van de Walle, ${ }^{{ }^{\dagger}}$ Aida Serrano, ${ }^{\ddagger} \S$ Sandra Preveral, , Christine Péchoux, ${ }^{\perp}$ David Pignol," Nicolas Menguy,// Christopher T Lefevre," Ana Espinosa,,$^{\S}{ }^{\dagger}$ and Claire Wilhelm**+

†. Laboratoire Matière et Systèmes, Complexes MSC, UMR 7057, CNRS \& University of Paris, 75205, Paris Cedex 13, France

‡ Spanish CRG beamline at the European Synchrotron (ESRF), B.P. 220, F-38043 Grenoble, France

§IMDEA Nanociencia, c/ Faraday, 9, 28049 Madrid, Spain

" Aix Marseille University, CNRS, CEA, UMR7265 Institute of Biosciences and Biotechnologies of Aix Marseille, CEA Cadarache, F-13108 Saint-Paul-lez-Durance, France.

$\perp$ INRA, UMR 1313 GABI, MIMA2-Plateau de Microscopie Electronique, 78352 Jouy-en-Josas, France

// Sorbonne Université, UMR CNRS 7590, MNHN, IRD, Institut de Minéralogie, de Physique des Matériaux et de Cosmochimie, IMPMC, 4 place Jussieu, 75005 Paris, France.

* AC and AVdW contributed equally to this work.

**Address correspondence to claire.wilhelm@univ-paris-diderot.fr 


\section{ABSTRACT}

The nanoparticles produced by magnetotactic bacteria, called magnetosomes, are made of a magnetite core with high levels of crystallinity surrounded by a lipid bilayer. This organized structure has been developed during the course of evolution of these organisms to adapt to their specific habitat, and is assumed to resist degradation, able to withstand the demanding biological environment. Herein, we investigated magnetosomes structural fate upon internalization in human stem cells using magnetic and photothermal measurements, electron microscopy, and X-ray absorption spectroscopy. All measurements first converge to the demonstration that intracellular magnetosomes can experience an important biodegradation, with up to $70 \%$ of their initial content degraded, and associated with the progressive storage of the released iron in the ferritin protein. It correlates with an extensive magnetite to ferrihydrite phase transition. The ionic species delivered by this degradation could then be used by the cells to biosynthesize magnetic nanoparticles anew. In this case, cells magnetism first decreased with magnetosomes being dissolved, but then cells re-magnetized entirely, evidencing the neo-synthesis of biogenic magnetic nanoparticles. Bacteria-made biogenic magnetosomes can thus be totally remodeled by human stem cells, into human cells-made magnetic nanoparticles.

\section{SYNOPSIS TOC}

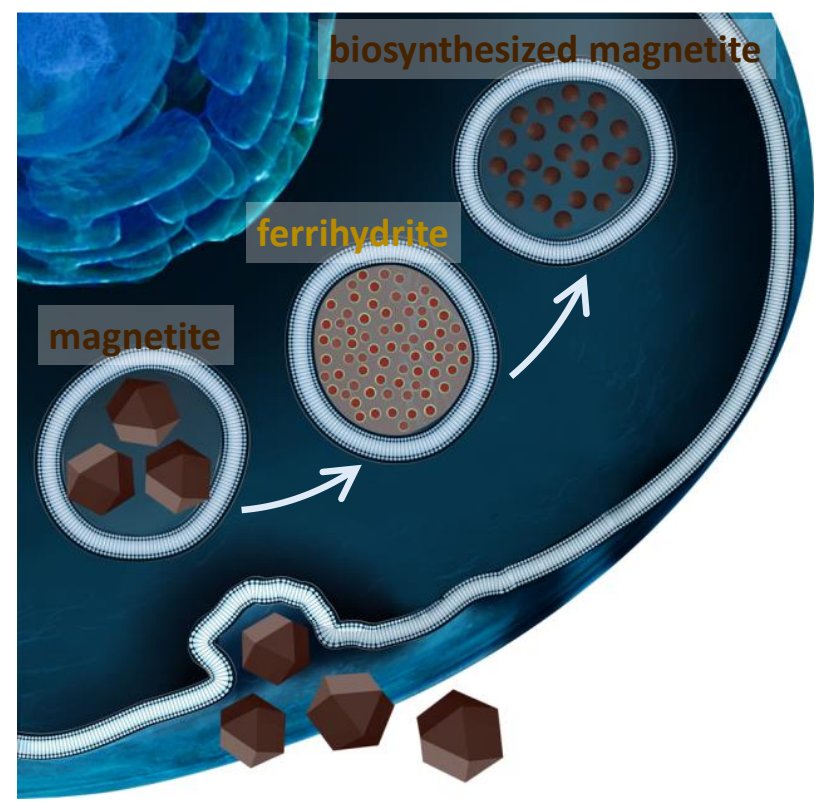

KEYWORDS magnetosomes, biodegradation, nanoparticles, magnetite, ferrihydrite, biosynthesis 
Iron oxide nanoparticles, due to their unique magnetic properties, remain key players for the development of advanced biomedical applications. However, comprehensive assessments of their stability and fate upon cell internalization are still limited. It has recently been demonstrated that they can be progressively degraded both in vivo and in cellulo, ${ }^{1-8}$ which allows for the released ions to fully integrate the metabolism of the organism in the long-term. These studies were mostly based on small synthetic nanoparticles (in the $10 \mathrm{~nm}$ range). How biogenic or biomimetic nanoparticles, supposed to endure the biological environment, are degraded or remain intact still needs to be unraveled. Herein, we investigated the stability and fate of bacteria-made magnetic inclusions, named magnetosomes, one of the most remarkable biomineralized nanoparticles. Magnetosomes are unique prokaryotic organelles that allow magnetotactic bacteria to align and swim along magnetic field lines. ${ }^{9}, 10$ The bacterial magnetosome and its magnetic properties have been refined and optimized during the course of evolution allowing the organisms that synthesize them to control their chemical composition, size and morphology, as well as their arrangement within the cell. ${ }^{9}, 11,12$ Consequently, magnetosomes exhibit a magnetite core of several tens of nanometers organized in a single magnetic domain, a high level of purity and crystallinity, a well-defined crystal morphology and they are surrounded by a 5-6 $\mathrm{nm}$ protein-rich phospholipid bilayer derived from the cytoplasmic membrane. ${ }^{13-15}$ This magnetosome membrane has been proven to protect the magnetite structure from oxidation, ${ }^{16}$ contrarily to synthetic nanoparticles in which the external layer tends to be oxidized. Deep investigations of the magnetosome biogenic synthesis have identified ferrihydrite as a chemical precursor of magnetite biomineralization, ${ }^{17}$ and an additional mechanism involving phase transformations into magnetite from disordered phosphate-rich ferric hydroxide consistent with prokaryotic ferritins was proposed. ${ }^{18}$ Finally, not only magnetosomes have been studied for their peculiar biosynthesis, but also they have been investigated for biomedical applications, ${ }^{19,} 20$ taking advantage of their excellent crystallinity and stability provided by the biological membrane together with the possibility to genetically engineer their surface. ${ }^{21,22}$ They are now considered amongst the best agents for magnetic hyperthermia, ${ }^{23}$ photothermia ${ }^{24,25}$, and magnetic resonance imaging. ${ }^{21,26,27}$ Besides, it was reported that magnetosomes display low toxicity, which has been due to their relatively insoluble magnetite core, ${ }^{28-30}$ and furthermore, magnetosomes can have peroxidase-like properties that scavenge cytotoxic reactive oxygen species (ROS). ${ }^{31,32}$ The question of the magnetosomes degradability however remains 
controversial, as a few studies also reported their progressive degradation over time, in protozoans, or in mice, ${ }^{19,33,34}$ but not yet in human cells.

In this study, we monitored the magnetosomes intracellular integrity in human stem cells over the course of a month. The magnetism of the cells was primarily used as quantitative fingerprint of the magnetosomes magnetic signature and photothermia was used as additional assessment of magnetosome integrity. Transmission electron microscopy (TEM) and high resolution TEM (HR-TEM) allowed to localize and monitor in situ the crystal structures at the nanoscale. Time-resolved X-ray absorption spectroscopy (XAS) studies in the near edge (XANES) and extended (EXAFS) regimes at the Fe K-edge provided the iron oxidation state during the long-term intracellular processing of the magnetosomes in the cells. ${ }^{35}$ Magnetosomes were internalized in human mesenchymal stem cells and the labeled cells were then maintained under two distinct culture conditions. First, the cells were assembled in a 3D cell-spheroid kept in medium supplemented with insulin, transferrin and selenous acid (ITS) to ensure the spheroids viability over months. Such culture method was previously used as a model to monitor synthetic nanoparticles degradation on the long-term and quantitatively. ${ }^{2,36}$ In this case, a progressive and extensive degradation of the magnetosomes occurred, associated with the change of iron oxidation state over 21 days detected by XAS and confirmed by HR-TEM.

Monolayer (2D) stem cells culture was next performed in absence of transferrin and selenium. In this condition, small (8-nm) synthetic nanoparticles were found to be transformed into de novo magnetic nanoparticles biosynthesized from degradation products. ${ }^{37}$ Under this culture conditions, magnetosomes were found to be degraded during the first days upon their internalization in stem cells, evidenced by the decrease of their magnetization (and at the same time their magnetite-mediated photothermal efficiency ${ }^{24}$ ), but a few days later, cells remagnetized almost totally (and re-generated heat equally): magnetic nanoparticles were being neo-synthesized. TEM and HR-TEM confirmed the presence of these newly biosynthesized nanoparticles, bearing a magnetite structure. Magnetosomes can thus be precursors of a biogenic synthesis of magnetic nanoparticles in human cells.

Magnetosomes are thus fully integrated in human stem cells where they are first converted from magnetite to ferrihydrite, the reverse cycle to the one observed during magnetosomes synthesis. ${ }^{17}$ Magnetosomes can then be biologically reshaped into neo-synthesized magnetic 
nanoparticles such as obtaining double bio-made magnetic nanoparticles: first synthesized in the bacteria then degraded in human stem cells prior to being biosynthesized anew.

\section{RESULTS AND DISCUSSION}

Magnetosomes are internalized in human stem cells and the cellular magnetization is the fingerprint of the intracellular dose

Low doses of magnetosomes (50-nm size range, Figure 1A) from 15 to $120 \mu \mathrm{M}$ of Fe were incubated with human mesenchymal stem cells for a short-time-period (30 min). Two hours upon internalization, cells observed by TEM displayed magnetosomes located only within the cytoplasm, confined in endosomes (Figures 1B and 1C, Figure S1). No magnetosome were observed outside the cells. Size analyses extrapolated from the TEM images (Figure 1D) indicated similar diameters for the magnetosomes observed before and after cell internalization, thus indicating that the process itself does not alter their structural integrity and that internalization is size-independent. Spheroids were then formed based on 200000 magnetosomes-containing cells each. In few hours the spheroids became cohesive, and their magnetization was measured at the single spheroid level revealing a ferromagnetic signal characteristic of magnetite nanocrystals (see Figure S2 for the hysteresis in the magnetization cycles). A linear dose-dependent intake was observed by saturation magnetization values (Figure $1 \mathrm{E}$, in $\mu \mathrm{emu}$, at room temperature) that increased with the incubation dose. These values can be directly converted into the mass $\left(\mathrm{pg}_{\mathrm{Fe}}\right.$ ) of magnetosomes per cell (using the magnetosomes mass magnetization of $86 \mathrm{emu} \mathrm{g}^{-1}$ of iron) as shown in Figure 1F, evidencing an efficient internalization.

\section{Time-resolved magnetization reveals first that magnetosomes can be degraded in human stem cells}

For the degradation model, the stem cells-based spheroids were cultured for 21 days in specific medium leading to tissue maturation (Figure $2 \mathrm{~A}$ ) and extracellular matrix production (Figure 2B). Magnetization at $300 \mathrm{~K}$ of the spheroids was measured at day 0 (right after the internalization, as showed in Figure $1 \mathrm{E}$ ) and at days 1, 3, 9, and 21 (Figures 2C and 2D, Figures S3 and S4). Average measurements of the saturation magnetization (more than 5 independent spheroids) are presented in Figure 2E for all initial doses. These values are a direct indicator 
of the magnetic integrity of the magnetosomes, therefore the decrease in magnetism reveals the degradation of their structure, as previously reported with other magnetic nanoparticles. ${ }^{2}$ Here, a progressive magnetization decrease from day 0 to day 21 was observed for all concentrations. Importantly, the intracellular degradation was found to be very significant, reaching almost up to $70 \%$ of the initial content. This relative quantity of degraded magnetosomes appears to be the inverse function of the initial intracellular content (Figure S5): for $1.3,2.4,5.3$ and $10 \mathrm{pg}$ of iron per cell, decreased degradation rates were at $69,64,57$ and $46 \%$, respectively. It indicates that the cells can only degrade a certain amount of magnetosomes relative to the initial dose. In addition, as most important to validate these results, we checked that the magnetic signal decrease was not due to magnetosome excretion out of the cells by performing ICP measurements over time. The total amount of iron in the spheroids was found to be constant until the last measurements after 21 days (Figure 2F). The decrease in magnetization is therefore only due to the dissolution of the magnetite core into non-magnetic iron compounds, and not to magnetosomes leakage from the cells, or from the spheroids. As additional analytical method, the magnetite-produced photothermal heating of the magnetosomes provided another indicator of their structural integrity (magnetite content), also confirming a progressive degradation of the magnetosomes (Figure $2 \mathrm{G}$ and $2 \mathrm{H}$ ).

\section{Electron microscopy observation confirms the degradation of magnetosomes and evidences the loading of released iron into ferritin}

TEM images were taken at day 21 for structural observation of the magnetosomes and their degradation products (Figure 3). First, the amount of intact magnetosomes observed at day 21 was much lower than at day 0 , for the same incubation concentration. Remaining magnetosomes appeared generally intact (high resolution TEM image shown in Figure S6), with average size of $42 \pm 10 \mathrm{~nm}$ (distribution presented in Figure S7), slightly reduced compared to day $0(46 \pm 9 \mathrm{~nm})$, but not significantly. More importantly, we noticed the presence of new, smaller structures, with spherical shape and mean diameter of $5.3 \pm 1.1 \mathrm{~nm}$ (distribution shown in Figure 3E), that were present in high number in both the cytoplasm and the endosomes at day 21 (Figure 3B for cytoplasm and Figure 3C and 3D for endosomes, more examples in Figure S8). EDS analysis was performed on a zone containing these small nanoobjects in endosomes and cytoplasm, revealing a significant presence of iron (Figure S9). Both size and iron content are typical of the ferritin protein complex loaded with iron, here 
originating from the magnetosomes degradation and absent at day 0 (Figure S1). This ferritin protein has already been identified as taking in charge and storing free iron released from the degradation of magnetic nanoparticles. ${ }^{2}$ Interestingly, its shell also provides a ferroxidase activity (H-subunit) allowing the oxidation of free $\mathrm{Fe}^{2+}$ ions to $\mathrm{Fe}^{3+}$ ions. Finally, analyzing gene expression by RT-PCR, we observed that this ferritin $\mathrm{H}$ subunit was significantly upregulated following magnetosomes degradation, in a dose-dependent manner (Figure 3F). Not only this confirms the implication of the ferritin in magnetosome degradation, but also indicates that the resulting $\mathrm{Fe}^{2+}$ ions were likely oxidized to produce $\mathrm{Fe}^{3+}$-based ferrihydrite in the ferritin. Importantly, nanocrystalline ferrihydrite is antiferromagnetic below $330 \mathrm{~K},{ }^{38}$ justifying the absence of its contribution to the magnetic signal of magnetite, thus the total magnetization decreases because of the transformation of the ferromagnetic magnetite signal into antiferromagnetic ferrihydrite.

\section{Time-resolved structural X-ray absorption and HR-TEM studies demonstrate the iron state transition, in the degradation model, from magnetite to ferrihydrite}

X-ray absorption spectra at the near-edge structure (XANES) and extended X-ray absorption fine structure (EXAFS) measurements were performed at the Fe K-edge $(7112 \mathrm{eV})^{39}$ to quantitatively investigate the iron phases over the maturation of the spheroid tissue. Because of the spheroid configuration, it was possible to handle it under synchrotron radiation, and perform the measurement at the spheroid scale. XANES allows probing the coordination and oxidation state of absorbing Fe ions while EXAFS gives information about their local environment, including the interatomic distances and the coordination numbers of surrounding shells. These two complimentary techniques can thus reveal the iron short-range geometry and identify the iron phases. ${ }^{35}$ They were recently applied to study biological systems. ${ }^{17,} 18,40$

Evolution of the XANES spectra during tissue maturation (days $0,3,9$, and 21) was assessed and compared to the magnetite and ferrihydrite reference spectra (Figures $4 A$ and $4 B$ and Figure S10). ${ }^{17,41}$ The XANES spectra showed a clear shift of the absorption edge over the 21 days of tissue maturation, direct evidence of iron oxidation. This shift is consistent with a change of iron oxide structure from magnetite (composed of $\mathrm{Fe}^{2+}$ and $\mathrm{Fe}^{3+}$ ) to ferrihydrite (composed of $\mathrm{Fe}^{3+}$ only). 
The XANES pre-edges features are reported in Figure 4B: the intensity variation indicates a gradual change on the symmetry around the Fe atoms over tissue maturation corroborating the change from magnetite (the most intense pre-edge peak) to ferrihydrite (the least intense pre-edge peak) due to their different percentage of Fe cations in tetrahedral sites. ${ }^{42}$

The Fourier transform (FT) for the EXAFS signals was also performed (Figure 4C), and the two distinct averaged distances corresponding to $\mathrm{Fe}-\mathrm{O}$ and Fe-Fe shells were analyzed. No trend is noticed in the first coordination shell (Fe-O) over the degradation time. By contrast, as the degradation time increased, the evolution of magnetosomes towards ferrihydrite was evidenced by the interatomic distance of the second coordination shell (Fe-Fe) that decreased and reduced its neighbors approaching to the values of ferrihydrite (see Figure 4D and Table S1), from a semi-quantitative analysis. It confirms the conversion from magnetite to ferrihydrite over time.

Additionally, HR-TEM analyses of intact magnetosomes observed at day 0 and its corresponding fast Fourier transform (FFT) (Figure 4E-F) displayed characteristic monocrystalline structure which has been indexed with a spinel cubic phase and its distinctive magnetite lattice parameters. On the contrary, at day 21 the interplanar distances deduced from FFT pattern obtained from the small ferritin-like nano-objects lattices were compatible with those of ferrihydrite structures (Figure 4G-N), and further validate the transition from magnetite in magnetosomes to ferrihydrite in ferritin upon degradation.

Such transition triggered in human stem cells recalls the reverse phenomenon occurring during magnetosomes (magnetite) biomineralization by magnetotactic bacteria, implicating a ferrihydrite intermediate. In that case, the ferrihydrite first produced is then reduced in magnetite, the opposite process to the one evidenced here. The iron structure thus circles back to its original ferrihydrite state when stored in the ferritin.

\section{Magnetosome biodegradation can be followed by endosomal biosynthesis of magnetic nanoparticles anew}

We next cultured the stem cells in monolayers (2D) over a period of 3 weeks, with limited cell division imposed by the selected medium. Importantly, this culture medium does not contain transferrin and selenium (contrary to the spheroid condition), which were shown to maintain the degradation process at the ferrihydrite-loaded ferritin stage, upon the typical iron metabolism pathway. In this culture condition, the ionic species delivered by degradation 
could also be used to induce a magnetic biogenic synthesis, as just demonstrated for small synthetic magnetic nanoparticles. ${ }^{37}$ After magnetosomes internalization, stem cells were seeded in well-plates and kept in culture for 21 days. The magnetism of these cells, measured after $1,3,9$, and 21 days of culture, demonstrated a different pattern from the previous degradation in spheroids: magnetization first decreased between day 0 and 3 , but then increased back to values close to the original ones at day 21 . The same pattern was observed for two initial intracellular magnetosome doses (corresponding to incubation concentrations of $[\mathrm{Fe}]=15 \mu \mathrm{M}$ and $60 \mu \mathrm{M})$. Figures $5 \mathrm{~A}$ and $5 \mathrm{~B}$ show typical magnetization curves for the two doses, and Figures $5 \mathrm{C}$ and $5 \mathrm{D}$ present the averaged saturation magnetization values over the time course of the experiment. It clearly evidences the re-magnetization phenomenon, with a decrease in magnetism during the first 1 to 3 days of culture reflecting an initial degradation of the magnetosomes followed by magnetism increase indicating the synthesis of magnetic nanoparticles anew, from the free iron released over the initial magnetosome degradation. The same protocol (biosynthesis condition) was implemented with human endothelial cells (HUVEC), evidencing no similar phenomenon. A decrease of the cellular magnetism over time was observed (Figure S11), suggesting that the magnetic nanoparticle biosynthesis could be stem cells specific. Photothermia was implemented as a second quantitative metrics to track the magnetosome transformations. Laser-mediated heating of the samples is shown in Figure $5 \mathrm{E}$, with average values presented in Figure 5F, and compared to the ones reached upon degradation only. It correlates perfectly with the biosynthesis pattern observed via magnetometry and definitely contrasts with the biodegradation situation. Moreover, it suggests that the biosynthesized nanoparticles are made of magnetite, because the photothermal potential of magnetic nanoparticles comes from the magnetite structure $\left(\mathrm{Fe}^{2+}\right.$ to $\mathrm{Fe}^{3+}$ valence band transition), and is much lower in the case of maghemite composition. ${ }^{43}$

Electron microscopy observations further evidenced the endosomal biosynthesis of magnetic nanoparticles anew. Figure 6 shows TEM images taken after 9 (Figure 6A-C) and 21 days (Figure 6D-F) of culture (see Figure S12 for additional images). It demonstrates the progressive formation of magnetic nanoparticles, confined in the endosomes. In particular, these nanoparticles appeared to be associated with specific subcellular compartments "fingerprint"like body rich of membranes tightly packed. These neo-synthesized nanoparticles are 7-8 nm in diameter (distribution shown in Figure 6G), are well defined, and are far from the original 
magnetosome structures. Finally, Figure $6 \mathrm{H}$ shows HR-TEM images of the newly biosynthesized nanoparticles, and Figure $6 I$ presents the HR-TEM electron diffraction profile of a zone containing only the biosynthesized nanoparticles. These particles displayed the distinctive rings of magnetite/maghemite composition, which further evidenced the magnetic biosynthesis of nanoparticles in human stem cells, using the ionic iron species delivered by magnetosome degradation. One remaining question concerns the fate of the biological membrane surrounding the magnetosomes prior to their internalization in stem cells, which can be clearly detected on TEM images when in solution (Figure S13). Thanks to uranyl acetate membrane staining, these magnetosome surrounding membranes can still be detected inside the cells the first days after their incorporation (Figures S14 and S15 at days 0 and 1, respectively). Their presence is less obvious at further days (Figures S16 and S17 at days 3 and 9, respectively), and almost none can be observed on remaining magnetosomes at day 21 (Figure S18). At day 21, the biosynthesized magnetic nanoparticles do not seem to present any biological shell (Figure S18), yet more difficult to detect due to their smaller size. However, it remains possible that these nanoparticles are integrated within the ferritin protein core. Fluorescence tracking of the Venus tag included in the magnetosome membranes was also performed over time (Figure S19) evidencing a delocalization from sharp endosomal confinement at day 0 to diffuse endosomal and cytoplasmic localization at day 21 .

\section{CONCLUSIONS}

With the ever increasing number of theranostics approaches using magnetosomes, it is crucial to understand their long-term fate after internalization in human cells. Here, we show that magnetosomes processing by human stem cells results in two biotransformation phenomena. In one case, magnetosomes are progressively degraded while iron state evolves from magnetite to ferrihydrite. Magnetic measurements and transmission electron microscopy indicate the appearance of 4-6 $\mathrm{nm}$ sized structures; these structures are shown to be ferrihydrite stored in the ferritin, which oxidize the free $\mathrm{Fe}^{2+}$ ions coming from magnetosomes degradation. In the second case, magnetosomes were first degraded but then dynamically transformed into magnetic nanoparticles biosynthesized in situ, within the endosomal compartments of the cells, evidenced by magnetic, photothermal, and HR-TEM analyses. The intracellular 
transition of the iron state from magnetite to ferrihydrite then cycles back to magnetite and demonstrates a complete transformation cycle of magnetosomes within human cells. Not only it reveals that magnetosomes can be degraded and fully integrate the iron metabolism of stem cells, but also that these cells are capable of biosynthesizing magnetic nanoparticles. This dissolution / biosynthesis mechanism resembles to the one observed with other nanomaterial compositions, such as hydroxyapatite nanocrystals that are fully dissolved and re-precipitate as needle-like crystallites within one day. ${ }^{44}$ The natural presence of magnetite nanoparticles has been detected in a variety of human cells including in the brain, heart, spleen, liver, ethmoid bone, and tumors, ${ }^{45-49}$ and has sometimes been designated as an indicator of neurodegenerative diseases. ${ }^{50-52}$ However, the reason for their presence remains unexplained. A recent study showed humans are capable of sensing the geomagnetic field of the Earth and correlates this feature with the presence of magnetite in the brain. ${ }^{53}$ It recalls the capacity of magnetotactic bacteria to align along the magnetic field of the Earth, a property that has largely been attributed to the magnetosomes. Here, the biosynthesis of magnetite nanoparticles in human cells, based on magnetosomes degradation products, may be one crucial step toward understanding a possible magnetoreception aptitude in humans. 


\section{MATERIALS AND METHODS}

\section{Magnetosomes production}

Magnetite magnetosomes were biosynthesized under strict genetic control by Magnetospirillum magneticum strain AMB-1 (ATCC700264). By genetic manipulation the Venus fluorescent reporter and the RGD peptide were inserted in the lipid membrane by genetic manipulation to enable the tracking of the membrane by fluorescence microscopy, and to enhance the cell internalization, respectively. ${ }^{21}$ Magnetosome production and purification were performed as already described. ${ }^{24}$ Briefly, the genetically modified AMB-1 bacterial strain was grown in a $6 \mathrm{~L}$ bioreactor and cells from late exponential-phase culture were harvested by centrifugation $\left(7500 \mathrm{G}, 10 \mathrm{~min}, 4^{\circ} \mathrm{C}\right)$. The pellet $(\approx 19 \mathrm{~g}$ per $6 \mathrm{~L}$ ) was resuspended in $100 \mathrm{~mL}$ of purification buffer (20 mM HEPES, $1 \mathrm{mM}$ EDTA, $0.9 \% \mathrm{NaCl}, 8 \%$ glycerol pH 7.5 in presence of a cocktail of proteases) then re-pelleted $\left(7500 \mathrm{G}, 10 \mathrm{~min}, 4^{\circ} \mathrm{C}\right)$. The cells were then disrupted 3 times with a French press $\left(1000 \mathrm{PSI}, 4^{\circ} \mathrm{C}\right)$. The tubes were left for $30 \mathrm{~min}$ at $4^{\circ} \mathrm{C}$ in contact of a magnet (MACSi-MAG ${ }^{\text {tm }}$ separator, Miltenyi Biotec), resulting in magnetosomes collection. The unretained fraction was removed and the magnetosome fraction was resuspended in $45 \mathrm{~mL}$ of buffer. This magnetic purification step was performed 5 times with buffer 1 (without anti protease) then 5 times with buffer 2 (20 mM HEPES, 0.9\% $\mathrm{NaCl}, 8 \%$ glycerol, $\mathrm{pH} 7.5)$. After the washing steps, the magnetosomes were resuspended in buffer 3 (20 mM HEPES, 8\% glycerol, pH 7.5), at a concentration of $3 \mathrm{~g} \mathrm{~L}^{-1}$ of iron and $100-\mu \mathrm{L}$ aliquots were flash-frozen in liquid nitrogen then stored at $-80^{\circ} \mathrm{C}$. As previously reported, this protocol ends up with magnetite nanoparticles. ${ }^{54}$

\section{Cell culture, magnetosomes internalization and long-term cell monitoring}

Human mesenchymal stem cells (hMSC) were purchased from Lonza and were cultured in hMSC-basal medium at $37^{\circ} \mathrm{C}, 5 \% p \mathrm{CO}_{2}$ and $95 \%$ relative humidity. At $90 \%$ confluence, cells were incubated with magnetosomes diluted in serum-free RPMI, previously sonicated for $5 \mathrm{~min}$ at $45 \mathrm{kHz}$ immediately after thawing. The iron concentration in the medium ranged from 15 to $120 \mu \mathrm{M}$. After 30 min incubation, the medium was removed and the cells were rinsed with serum-free RPMI and incubated further for $2 \mathrm{~h}$ in complete hMSC-basal medium to remove any non-internalized magnetosomes. Then, cells were detached by trypsinization, counted and seeded. For the biodegradation condition, cells were separated in $15 \mathrm{~mL}$ tubes ( $2 \times 10^{5}$ cells per tube), centrifuged (1200 RPM for $5 \mathrm{~min}$ ) to form a pellet, and cultured in 1.5 
$\mathrm{mL}$ of medium for 21 days with medium replenished twice a week. For this condition, the medium was composed of high glucose DMEM supplemented with $1 \%$ penicillinstreptomycin, $0.1 \mu \mathrm{M}$ dexamethasone, $1 \mathrm{mM}$ sodium pyruvate, $50 \mu \mathrm{M}$ L-ascorbic acid 2phosphate, $0.35 \mathrm{mM}$ L-proline (Sigma), 1\% ITS-Premix (Corning), and $10 \mathrm{ng} / \mathrm{mL}$ TGF- $\beta 3$ (Interchim). For the biosynthesis condition, cells were seeded in 6 -well plates $\left(2 \times 10^{5}\right.$ cells per well) and cultured in $1.5 \mathrm{~mL}$ of medium. For this condition, two independent media were prepared. The first consisted of high glucose DMEM (Dulbecco's Modified Eagle Medium) (Thermo Fischer Scientific) supplemented with 10\% FBS, 1\% penicillin and streptomycin (Thermo Fischer Scientific), $10 \mathrm{ng} / \mathrm{mL}$ insulin (Sigma), $1 \mu \mathrm{M}$ dexamethasone (Sigma), $200 \mu \mathrm{M}$ indomethacin (Sigma), and $500 \mu \mathrm{M}$ isobutyl methylxanthine (Sigma). The second was made of high glucose DMEM supplemented with $10 \%$ FBS, $1 \%$ penicillin-streptomycin, and $10 \mathrm{ng} / \mathrm{mL}$ insulin. Cells were cultured in the first medium for three to four days followed by the second for three days. The treatment allowed to limit cell proliferation and was repeated three times then cells were maintained in the second medium until day 21 , with media replenished twice a week. The cells were fixed in $5 \%$ glutaraldehyde diluted in $0.1 \mathrm{M}$ cacodylate buffer overnight at $4^{\circ} \mathrm{C}$ at given time points: right after labeling with magnetosomes (Day 0), and at days 1,3 , 9 and 21.

\section{Quantification of the internalized magnetic iron by VSM}

Magnetic iron in the hMSCs right after magnetosomes incubation and in samples fixed at different maturation times was systematically measured by magnetometry using a PPMS device equipped with a vibrating sample magnetometer (VSM) option (Quantum Design). The analysis was performed at $300 \mathrm{~K}$, between 0 and $25000 \mathrm{Oe}$ and provides the saturation magnetization of the sample (in emu), giving directly the amount of magnetic iron (in grams) based on the magnetosomes saturation magnetization ( $86 \pm 3 \mathrm{emu} \mathrm{g}^{-1}$ ). To evaluate further the hysteresis loop of the ferromagnetic magnetosomes upon field shift, a cyclic magnetometry analysis was also performed from 1500 Oe to -1500 Oe and back to 1500 Oe.

\section{Quantification of the internalized total iron by ICP}

Total iron content was analyzed by elemental analysis of the samples using ICP-AES (iCAP 6500, Thermo). The cells at different stage of maturation (days 1, 3, 9 and 21) were digested in concentrated $\mathrm{HNO}_{3}$ and recovered with a $2 \% \mathrm{HNO}_{3}$ water solution. 
Transmission electron microscopy of magnetosomes and by-products of their degradation The samples fixed at day 0 and day 21 were contrasted with Oolong Tea Extract (OTE) $0.5 \%$ in $0.1 \mathrm{M} \mathrm{Na}$ cacodylate buffer, post-fixed with $1 \%$ osmium tetroxide containing $1.5 \%$ potassium cyanoferrate, gradually dehydrated in ethanol (30\% to $100 \%)$ and gradually embedded in epoxy resins. Ultrathin slices $(70 \mathrm{~nm})$ were collected onto 200 mesh copper grids and counterstained with lead citrate prior to being observed with a Hitachi HT 7700 TEM operated at $80 \mathrm{kV}$ and images were acquired with a charge-coupled device camera (AMT). The sizes of the nanoparticles at Day 0 (compared with the one of the magnetosomes in solution) and of the magnetosomes and iron deposits in the ferritins at Day 21 were measured by the Image J software (at least 400 diameters measured per condition). The same procedure without the lead counterstain have been applied for the preparation of the high-resolution TEM samples, which have been observed with a JEOL $2100 \mathrm{~F}$ operating at $200 \mathrm{kV}$, equipped with a Schottky emission gun, an ultra-high-resolution pole piece, and a Gatan US 4000 CCD camera.

\section{Ferritin Heavy chain expression by Real-Time PCR}

Total RNA was extracted from spheroids formed from cells incubated with magnetosomes at [Fe] $=0$ (control), 30 and $60 \mu \mathrm{M}$ and after 9 days of maturation. The extraction was carried out using a NucleoSpin RNA II kit (Macheney-Nagel) according to the manufacturer's instruction. Reverse transcription into cDNA was achieved using SuperScript II reverse transcriptase (Invitrogen) according to the manufacturer's instructions. qPCR was performed with StepOnePlus (Applied Biosystems) using the SYBR Green reagent (Applied Biosystems). The expression of reference gene RPLPO was used as internal normalizer. The sequences of primers used are:

RPLPO fwd: 5' TGC ATC AGT ACC CCA TTC TAT CAT 3'

RPLPO rev: 5' AAG GTG TAA TCC GTC TCC ACA GA 3'

FerrH fwd: 5' TG GCT TGG CGG AAT TTC TGT 3'

FerrH rev: 5' GC CCG AGG CTT AGC TTT CAT 3'

\section{Laser-induced heating measurements}

Photothermal analysis of samples at different maturation stages was carried out using a 808$\mathrm{nm}$ CW laser diode coupled to an optic fiber (Laser Components S.A.S). Fixed samples were suspended in $5 \mu \mathrm{L}$ PBS in a $0.5 \mathrm{~mL}$ tube and were illuminated with a power density of $0.3 \mathrm{~W}$ $\mathrm{cm}^{-2}$ for $2 \mathrm{~min}$. The temperature elevation $(\Delta \mathrm{T})$ was recorded using an infrared thermal 
imaging camera (FLIR SC7000). A decrease in photothermal efficiency is an indirect proof of the magnetosomes degradation and of their biotransformation from a more (magnetite) to a less (ferrihydrite) plasmonic material. ${ }^{36}$

\section{XANES/EXAFS analysis (Synchrotron radiation)}

XAS measurements were performed on the biodegradation samples that consist in dense cellpellets easily transferable, by contrast with the independent cells of the biosynthesis model. Analyses were carried out at the CRG beamline BM25-SpLine of the European Synchrotron Radiation Facilities (ESRF) in Grenoble (France). The sample spectra were measured at the Fe K-edge $(7112 \mathrm{eV})$ at room temperature in the fluorescence mode. The energy was calibrated with the energy edge position of a Fe foil. Magnetite, ferrihydrite and maghemite standards were chosen as references (shown in Figure S10). From 4 to 5 spheroids were used to obtain the sample spectra at different maturation time. Several scans were taken in order to obtain a good signal-to noise ratio. Data analysis was carried out using Athena program ${ }^{4}$ identifying the beginning of the absorption edge, $E_{0}$, and the pre-edge and post-edge backgrounds. The spectra were subjected to a background subtraction and normalized by the edge jump. In the XANES regime, the edge position of samples was analyzed since it is an indication of the average oxidation state of $\mathrm{Fe}$, with edge increasing to higher energies when the oxidation state is incremented. On the other hand, the XANES pre-edge peak increases in intensity as the degree of non-centrosymmetry of the absorbing atom environment increases, e.g. in presence of a tetrahedral site. Magnetite is a spinel iron oxide where Fe cations occupy twice octahedral sites than tetrahedral sites, while in ferrihydrite the tetrahedral Fe occupies a lower percentage. The software Arthemis ${ }^{55}$ was used to process the EXAFS signal as a function of the modulus of the photoelectron wavevector, $\mathrm{k}, \chi(\mathrm{k})$ in the range of 2.8 and $9.5 \AA^{-1}$. The amplitude reduction factor $S_{0}^{2}$, the interatomic distance $R$ and the Debye-Waller (DW) factor $\sigma^{2}$ for the two shell distances are used as free parameters for each fitting.

\section{Statistical analysis}

All values are reported as means and standard error of the mean. Significant differences were determined using a Tukey's test in one-way analysis of variance (ANOVA).

\section{ASSOCIATED CONTENT}

\section{Supporting Information}


The Supporting Information is available free of charge on the ACS Publications website at DOI:

It contains additional TEM images (Figures S1, S8, S12, S13, S14, S15, S16, S17 and S18), additional HR-TEM and EDS analysis (Figure S6 and Figure S9, respectively), typical magnetization curves (Figures S2, S3 and S4), the analysis of the degradation rate as a function of the dose (Figure S5), the size distribution of magnetosomes in cells (Figure S7), the XANES absorption reference spectra (Figure S10), the analysis of cellular magnetism over time for endothelial cells (Figure S11), confocal microscopy visualization of the Venus probe embedded in the magnetosome membrane (Figure S19) and parameters extracted from the EXAFS experiment (Table S1).

\section{ACKNOWLEDGEMENTS}

This work was supported by the European Union (ERC-2014-CoG project MaTissE \#648779). The authors acknowledge the staff of the MPBT (physical properties - low temperature) plateform of Sorbonne Université for their support. We thank Nathalie Luciani and Anouchka Plan Sangnier for help and fruitful discussions. We acknowledge The ESRF for beamtime and the CRG beamline BM25-SpLine personnel for technical support, and AE acknowledges support from Comunidad de Madrid (Talento project 2018-T1/IND-1005).

\section{FIGURES}



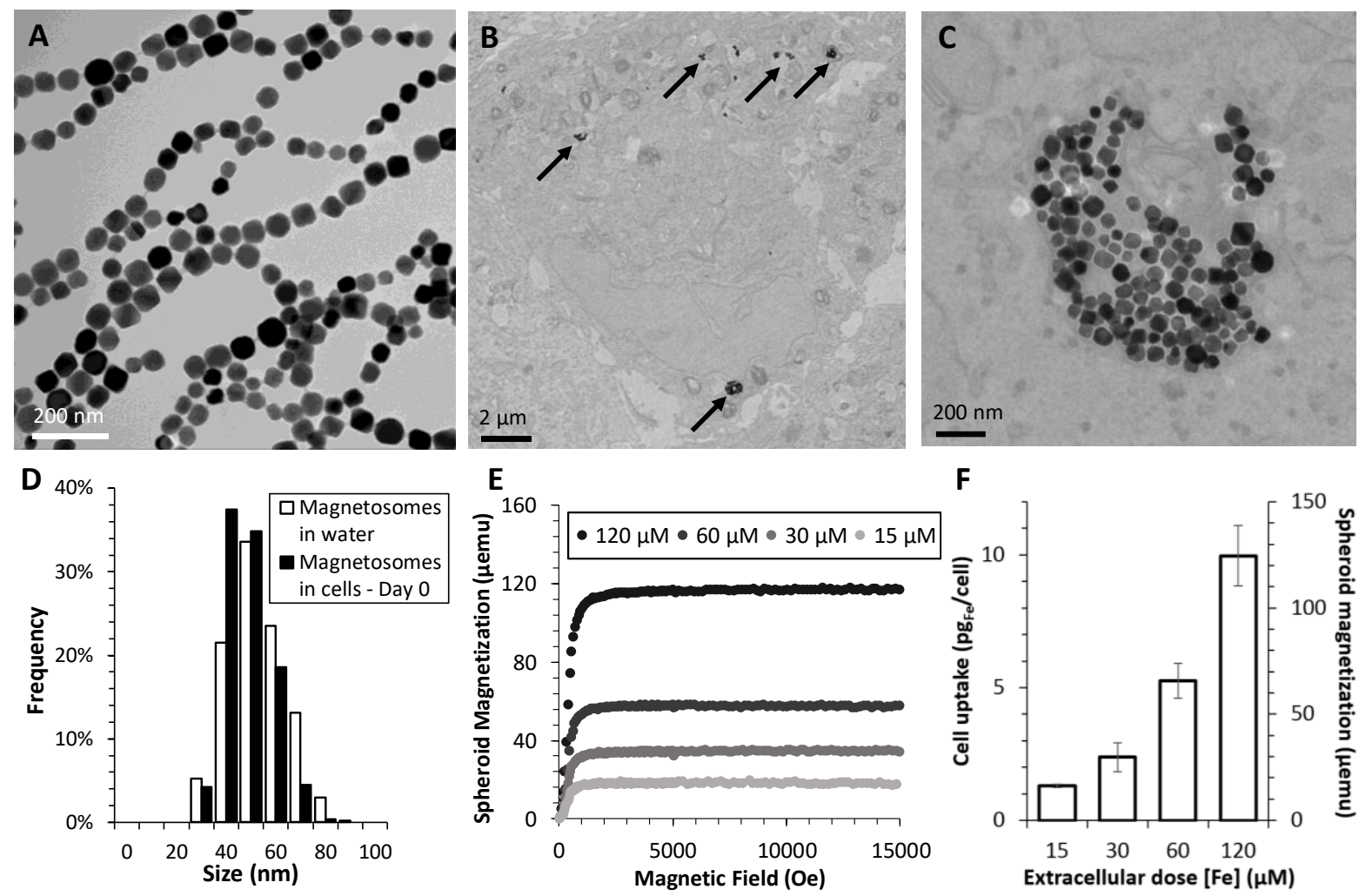

Figure 1: Magnetosomes internalization in human stem cells. Magnetosomes were incubated with human stem cells for $30 \mathrm{~min}$ at $[\mathrm{Fe}]=15,30,60,120 \mu \mathrm{M}$ ). (A) TEM images of the magnetosomes after purification and before internalization in cells. (B,C) TEM images of cells 2 hours after magnetosomes internalization (condition $60 \mu \mathrm{M}$ ), revealing magnetosomes endosomal location and allowing their size analysis before and right after cell uptake, showing no substantial difference (D). (E) Magnetization curves at $300 \mathrm{~K}$ of 200000 cells obtained by VSM magnetometry $2 \mathrm{~h}$ after incubation at difference Fe concentrations. Magnetization at saturation can be converted into mass of iron per cell (F), which increased linearly with the incubation dose. 
A

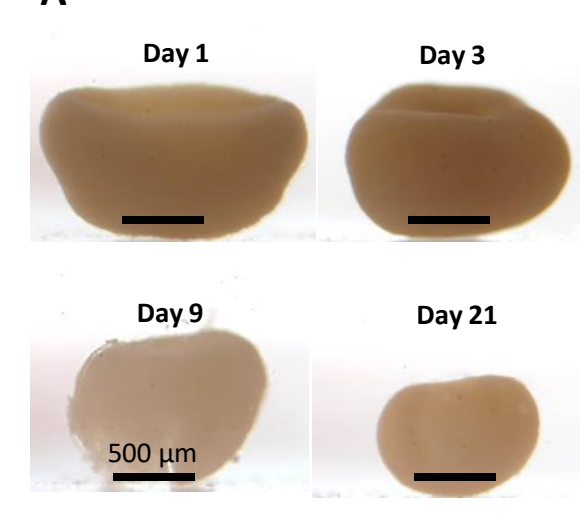

C

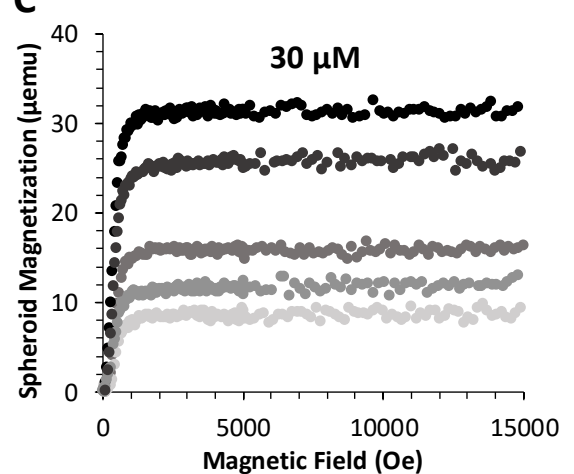

$\mathbf{E}$

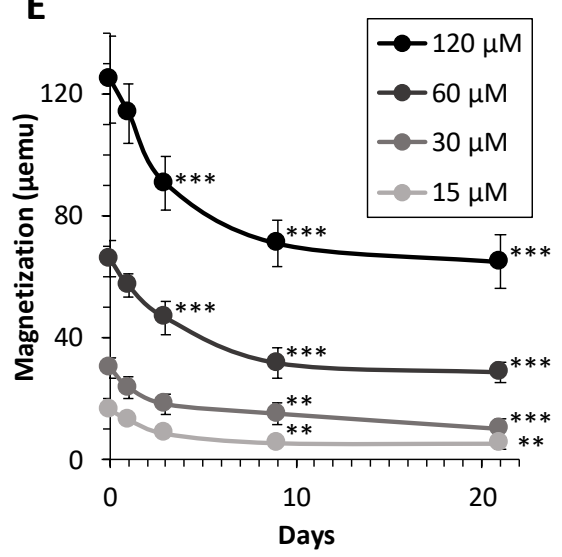

G

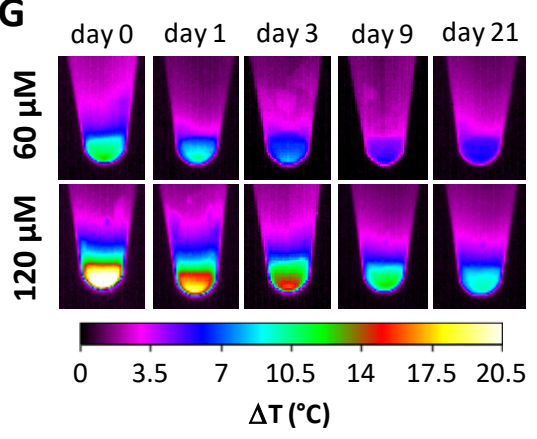

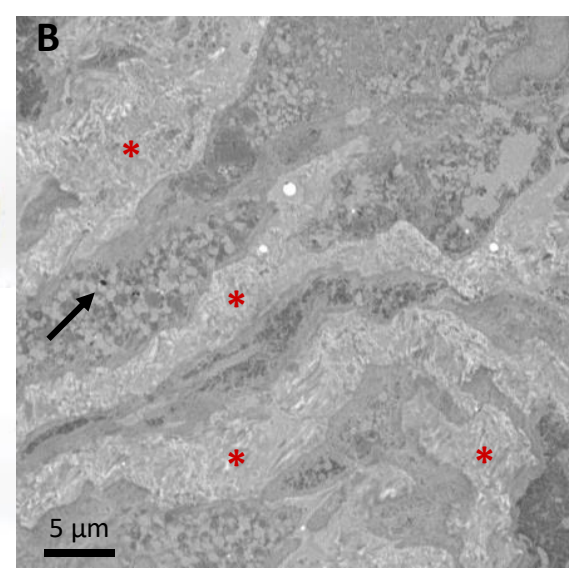

D

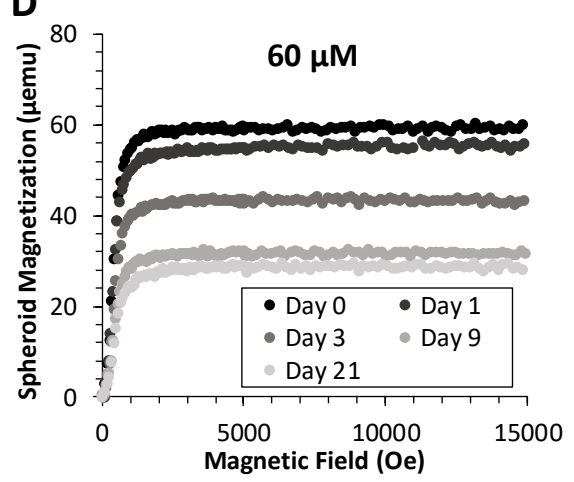

$\mathbf{F}$
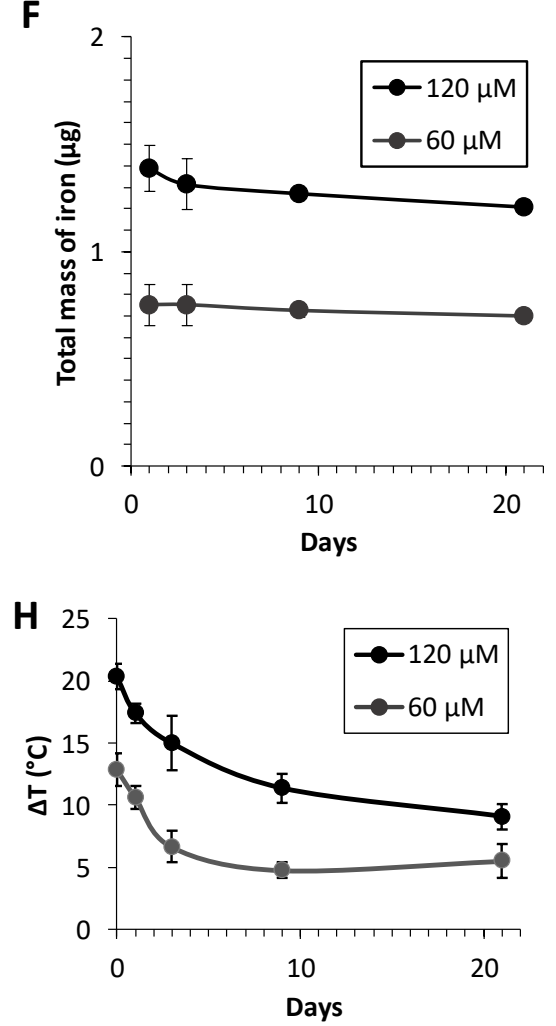

Figure 2: Magnetosomes biodegradation over tissue maturation. (A) Images of the spheroids formed with 200000 human stem cells showing the progressive formation of a cohesive tissue over the 21 days of culture. (B) At day 21, TEM showed an important production of 
extracellular matrix (red asterisks), with much less magnetosomes, remaining within endosomes (black arrow). (C-D) Representative single-spheroid magnetization curves over time for two incubation doses ( 30 and $60 \mu \mathrm{M}$ of Fe). (E) Average saturation magnetization for all incubation doses, as a function of days of maturation $(n=5, * * * p<0.001, * * p<0.005$, * p<0.05). (F) Total iron analysis per single spheroid by ICP performed during spheroid maturation $(n=5)$. (G) Representative IR images of the photothermal heating of a single spheroid after 2 min irradiation with $808 \mathrm{~nm}$ laser at the power density of $0.3 \mathrm{~W} \mathrm{~cm}^{-2}$ and $(\mathrm{H})$ corresponding average temperature increase for the concentrations of 60 and $120 \mu \mathrm{M}$ of Fe. 

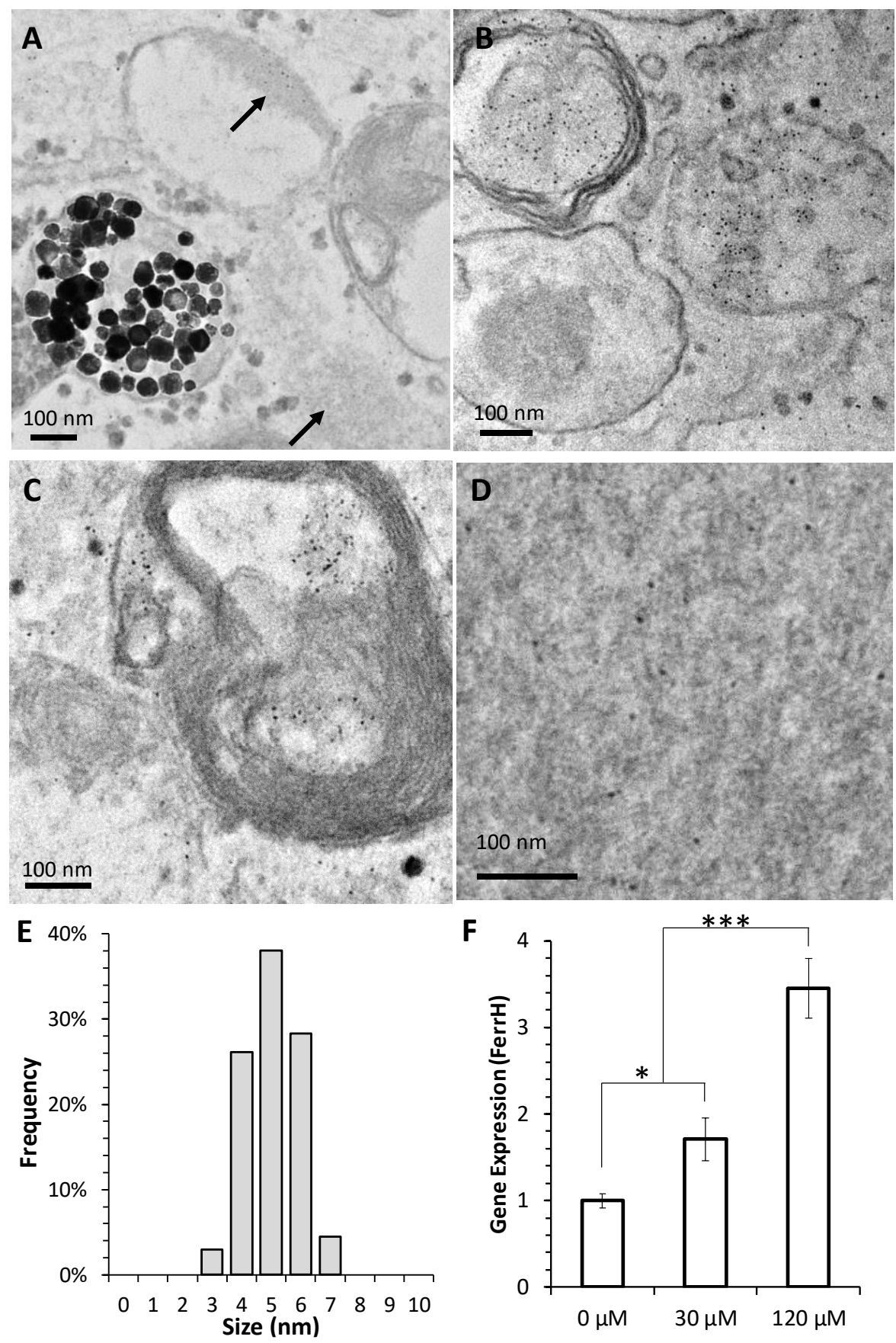

Figure 3: Magnetosomes transformations after 21 days of tissue maturation in the biodegradation model. (A-D) TEM images at day 21. (A) By comparison to day 0, only a few intact magnetosomes remained at day 21, with the systematic presence of smaller nanoparticles nearby (arrows). These smaller nanoparticles were observed both in the endosomes (B,C) and in the cytoplasm ( $D$, as well as $A-C$ outside the endosomes). (E) Size analysis based on the TEM images of the ferritin-like small nano-objects, ranging from 4 to 6 $\mathrm{nm}$, typical size of the iron storage protein. (F) Overexpression of the H-subunit of ferritin observed at day 21 for two initial doses of magnetosomes (incubation at [Fe] $=30$ and 120 $\mu \mathrm{M} ; * \mathrm{p}<0.05, * * * \mathrm{p}<0.001)$. 

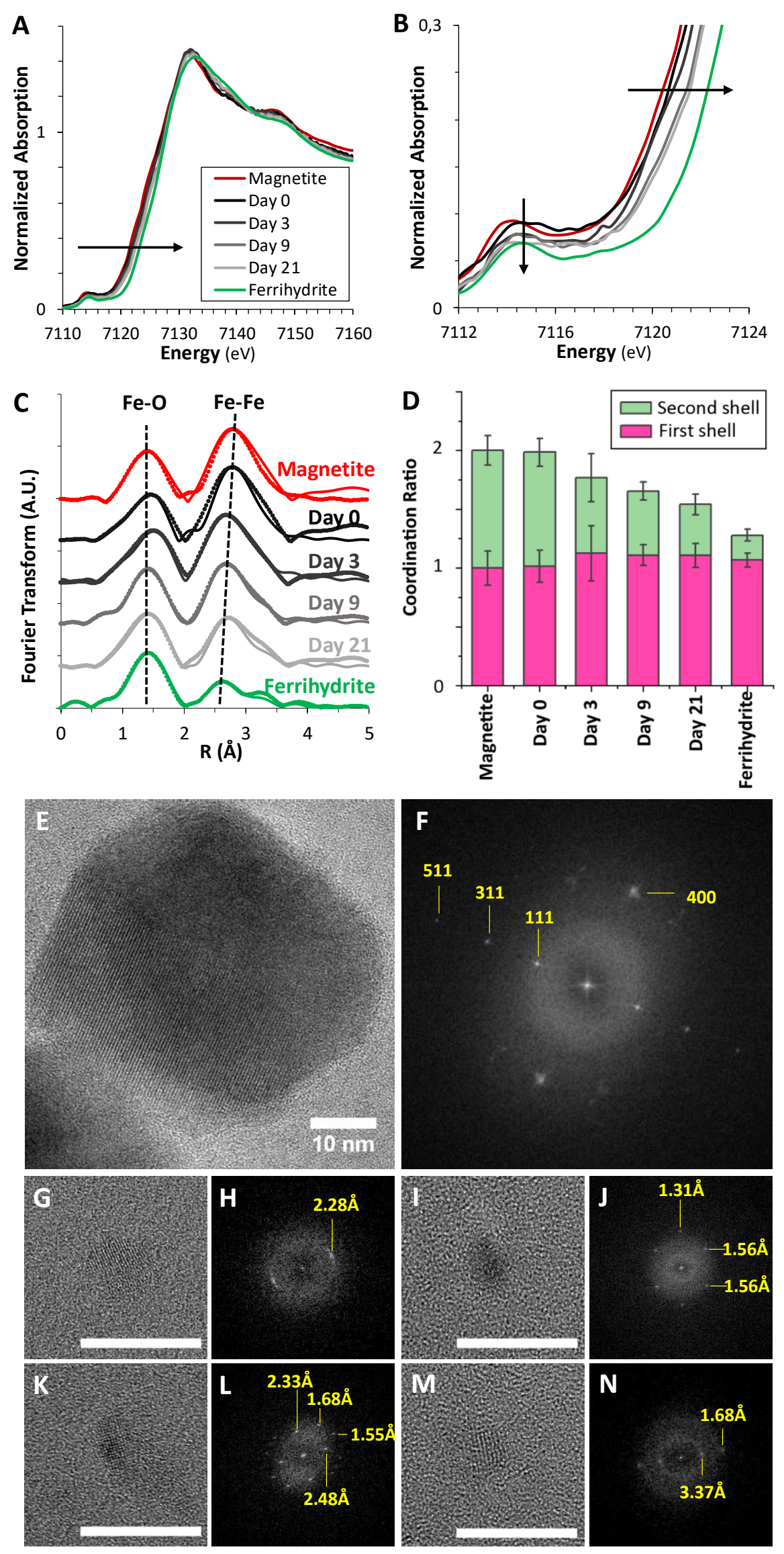
Figure 4: Degradation of the magnetosomes over tissue maturation associated with a transition of the iron oxide structure from magnetite to ferrihydrite. The iron phases were followed using XANES and EXAFS analyses (at the ESRF synchrotron facilities, CRG beamline BM25-SpLine). (A-B) XANES absorption spectra at the Fe K-edge displayed the shift of absorption edge in iron phases that coincides with the transition from the magnetite to the ferrihydrite structure. (C) Modulus of the FT of the EXAFS signal (dashed lines) and fitting simulations (continuous lines) showed similar results, with an iron structure that was progressively shifted from magnetite to ferrihydrite. (D) Coordination ratio of the first and second shell of samples and references obtained from experimental EXAFS fitting measurements at room temperature. (E) HR-TEM images of intact magnetosomes at day 0 and (F) the corresponding indexed FFT pattern in which the interplanar distances can be indexed to common lattice planes in the magnetite crystal structure. (G-N) HR-TEM images of the products of magnetosomes degradation located in the endosomes at day 21 and their corresponding indexed FFT pattern in which the interplanar distances are given with uncertainties equal to $0.05 \AA$ and correspond to interplanar distances in ferrihydrite: $(H) d_{014}$ $=2.237 \AA$, (J) $\mathrm{d}_{040}=1.289 \AA$, $\mathrm{d}_{006}=1.602 \AA,(\mathrm{L}) \mathrm{d}_{022}=2.281 \AA \mathrm{d}_{032}=1.635 \AA, \mathrm{d}_{033}=1.521 \AA$, $\mathrm{d}_{004}=2.471 \AA$, $(\mathrm{N}) \mathrm{d}_{032}=1.635 \AA, \mathrm{d}_{012}=3.410 \AA$. Scale bar $=10 \mathrm{~nm}$. 
A

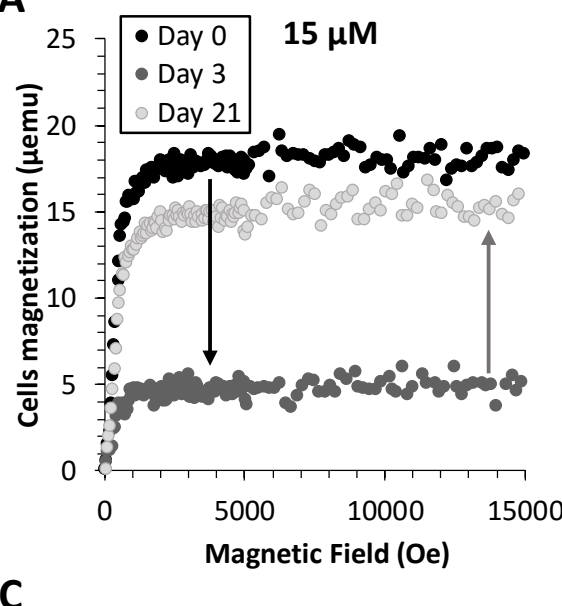

C

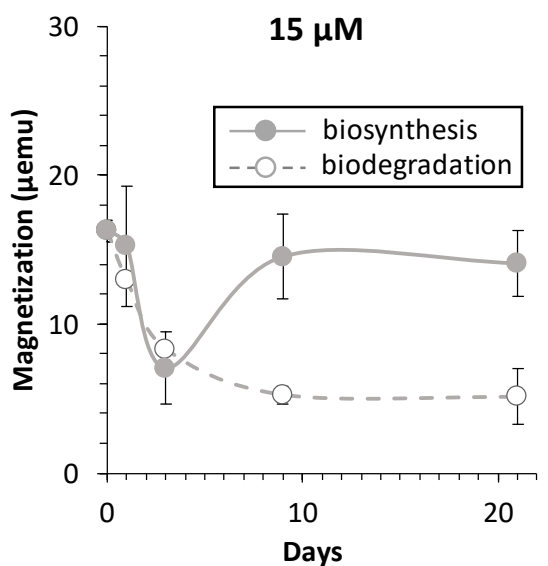

E
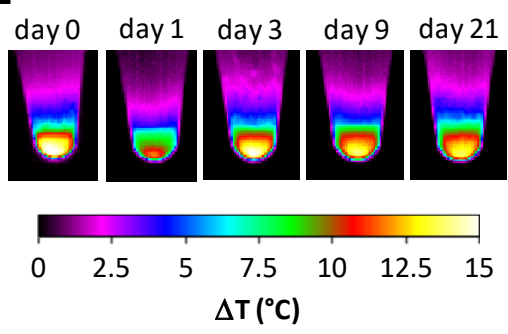

B

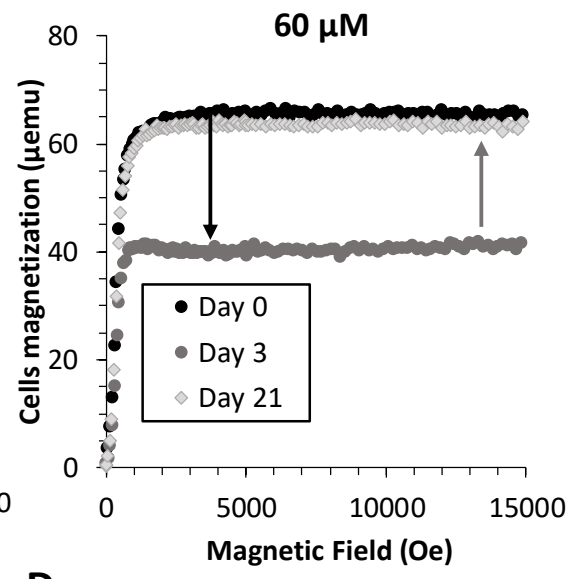

D
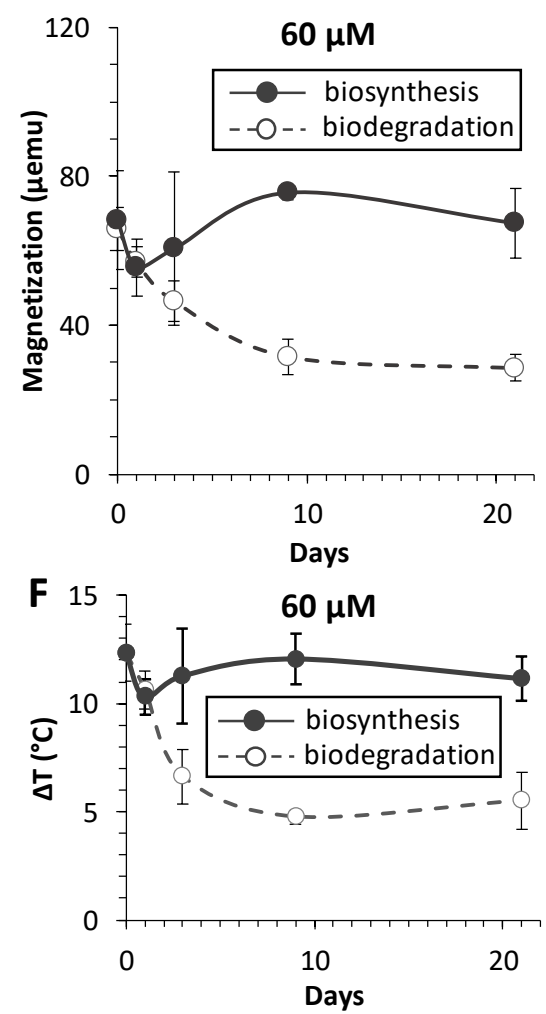

Figure 5: Initial loss and successive recovery of magnetization and heating under biosynthesis culture conditions. (A-B) Representative magnetization curves of 200000 cells labeled with $15 \mu \mathrm{M}(\mathrm{A})$ and $60 \mu \mathrm{M}$ (B) of iron and cultured in 2D without ITS. (C-D) Average saturation magnetization, as a function of time (in days) for the incubation at $15 \mu \mathrm{M}$ (C) and $60 \mu \mathrm{M}$ of Fe (D). For comparison, the curves obtained with the biodegradation model are superimposed (dotted line) for each condition. (E) Representative IR images of the thermometric analysis of 200000 cells doped with magnetosomes at $60 \mu \mathrm{M}$ of $\mathrm{Fe}$ and illuminated with $808 \mathrm{~nm}$ laser at $0.3 \mathrm{~W} \mathrm{~cm}^{-2}$ for $2 \mathrm{~min}$ at days $0,1,3,9$ and 21 for the biodegradation and biosynthesis anew models and $(F)$ the corresponding generated heat. 

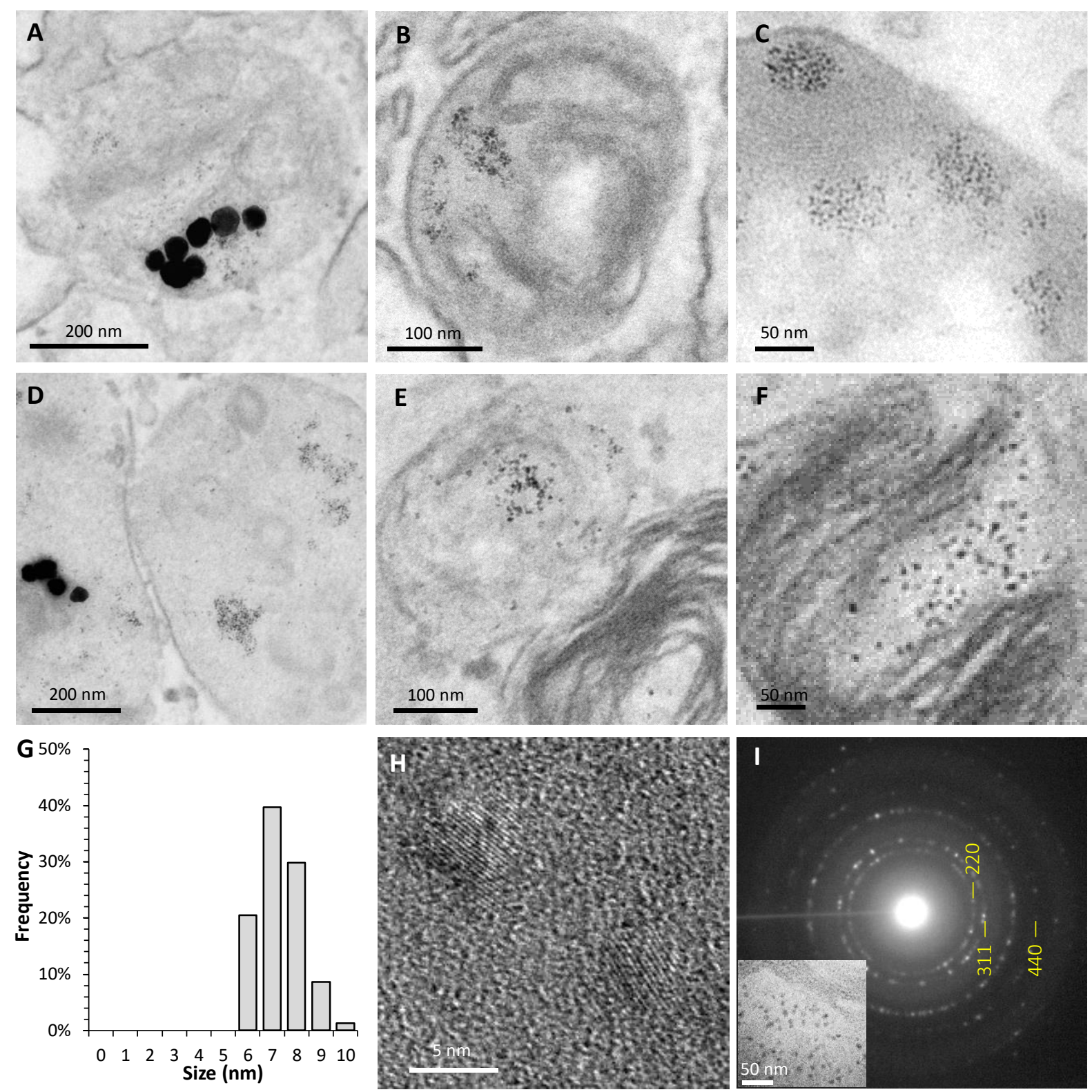

Figure 6: Neo-synthesis of magnetic nanoparticles in cellulo upon magnetosomes degradation. (A-F) TEM images of MSCs labeled with magnetosomes and cultured for 9 days (A-C) or 21 days (D-F) under the biosynthesis condition. Some intact magnetosomes could still be detected ( $A$ for day 9, D for day 21), but in most membrane-rich endosomes, nanoparticles were transformed into packed dark grey dot of diameter about 8-9 nm (B-C for day 9, E-F for day 21). (G) Size distribution of the biosynthesized nanoparticles. (H-I) Observation with HRTEM at day 21: high-resolution view showing the planar ultrastructure $(\mathrm{H})$ and the electron diffraction pattern (I) of the small zone in inset, in agreement to the structural parameters of magnetite/maghemite cubic phase. 


\section{REFERENCES}

1. Kolosnjaj-Tabi, J.; Lartigue, L.; Javed, Y.; Luciani, N.; Pellegrino, T.; Wilhelm, C.; Alloyeau, D.; Gazeau, F., Biotransformations of Magnetic Nanoparticles in the Body. Nano Today 2016, 11, 280284.

2. Mazuel, F.; Espinosa, A.; Luciani, N.; Reffay, M.; Le Borgne, R.; Motte, L.; Desboeufs, K.; Michel, A.; Pellegrino, T.; Lalatonne, Y., Massive Intracellular Biodegradation of Iron Oxide Nanoparticles Evidenced Magnetically at Single-Endosome and Tissue Levels. ACS Nano 2016, 10, 7627-7638.

3. Feliu, N.; Docter, D.; Heine, M.; del Pino, P.; Ashraf, S.; Kolosnjaj-Tabi, J.; Macchiarini, P.; Nielsen, P.; Alloyeau, D.; Gazeau, F.; Stauber, R. H.; Parak, W. J., In Vivo Degeneration and the Fate of Inorganic Nanoparticles. Chem. Soc. Rev. 2016, 45, 2440-2457.

4. Mejías, R.; Gutiérrez, L.; Salas, G.; Pérez-Yagüe, S.; Zotes, T. M.; Lázaro, F. J.; Morales, M. P.; Barber, D. F., Long Term Biotransformation and Toxicity of Dimercaptosuccinic Acid-Coated Magnetic Nanoparticles Support Their Use in Biomedical Applications. J. Control. Release 2013, 171, $225-233$.

5. $\quad$ Ruiz, A.; Gutiérrez, L.; Cáceres-Vélez, P.; Santos, D.; Chaves, S.; Fascineli, M.; Garcia, M.; Azevedo, R.; Morales, M., Biotransformation of Magnetic Nanoparticles as a Function of Coating in a Rat Model. Nanoscale 2015, 7, 16321-16329.

6. Carrillo-Carrion, C.; Bocanegra, A. I.; Arnaiz, B.; Feliu, N.; Zhu, D.; Parak, W. J., Triple-Labeling of Polymer-Coated Quantum Dots and Adsorbed Proteins for Tracing Their Fate in Cell Cultures. ACS Nano 2019, 13, 4631-4639.

7. Soenen, S. J.; Parak, W. J.; Rejman, J.; Manshian, B., (Intra) Cellular Stability of Inorganic Nanoparticles: Effects on Cytotoxicity, Particle Functionality, and Biomedical Applications. Chem. Rev. 2015, 115, 2109-2135.

8. Manshian, B. B.; Pokhrel, S.; Mädler, L.; Soenen, S. J., The Impact of Nanoparticle-Driven Lysosomal Alkalinization on Cellular Functionality. J. Nanobiotech. 2018, 16, 85.

9. Uebe, R.; Schüler, D., Magnetosome Biogenesis in Magnetotactic Bacteria. Nat. Rev. Microbiol. 2016, 14, 621.

10. Bazylinski, D. A.; Frankel, R. B., Magnetosome Formation in Prokaryotes. Nat. Rev. Microbiol. 2004, 2, 217.

11. Lefèvre, C. T.; Wu, L.-F., Evolution of the Bacterial Organelle Responsible for Magnetotaxis. Trends Micobiol. 2013, 21, 534-543.

12. Orue, I.; Marcano, L.; Bender, P.; García-Prieto, A.; Valencia, S.; Mawass, M.; Gil-Cartón, D.; Venero, D. A.; Honecker, D.; García-Arribas, A.; Fernández Barquín, L.; Muela, A.; Fdez-Gubieda, M., Configuration of the Magnetosome Chain: A Natural Magnetic Nanoarchitecture. Nanoscale 2018, 10, 7407-7419.

13. Gorby, Y. A.; Beveridge, T. J.; Blakemore, R. P., Characterization of the Bacterial Magnetosome Membrane. J. Bacteriol. 1988, 170, 834-841.

14. Komeili, A.; Li, Z.; Newman, D. K.; Jensen, G. J., Magnetosomes Are Cell Membrane Invaginations Organized by the Actin-Like Protein Mamk. Science 2006, 311, 242-245.

15. Cornejo, E.; Abreu, N.; Komeili, A., Compartmentalization and Organelle Formation in Bacteria. Curr. Opin. Cell Biol. 2014, 26, 132-138.

16. Fischer, A.; Schmitz, M.; Aichmayer, B.; Fratzl, P.; Faivre, D., Structural Purity of Magnetite Nanoparticles in Magnetotactic Bacteria. J. R. Soc. Interface 2011, 8, 1011-1018.

17. Fdez-Gubieda, M. L.; Muela, A.; Alonso, J.; García-Prieto, A.; Olivi, L.; Fernández-Pacheco, R.; Barandiarán, J. M., Magnetite Biomineralization in Magnetospirillum Gryphiswaldense: Time-

Resolved Magnetic and Structural Studies. ACS Nano 2013, 7, 3297-3305.

18. Baumgartner, J.; Morin, G.; Menguy, N.; Gonzalez, T. P.; Widdrat, M.; Cosmidis, J.; Faivre, D., Magnetotactic Bacteria Form Magnetite from a Phosphate-Rich Ferric Hydroxide Via Nanometric Ferric (Oxyhydr) Oxide Intermediates. Proc. Nat. Acad. Sc. USA 2013, 110, 14883-14888. 
19. Alphandéry, E., Applications of Magnetosomes Synthesized by Magnetotactic Bacteria in Medicine. Front. Bioeng. Biotech. 2014, 2, 5.

20. Le Fèvre, R.; Durand-Dubief, M.; Chebbi, I.; Mandawala, C.; Lagroix, F.; Valet, J.-P.; Idbaih, A.; Adam, C.; Delattre, J.-Y.; Schmitt, C., Enhanced Antitumor Efficacy of Biocompatible Magnetosomes for the Magnetic Hyperthermia Treatment of Glioblastoma. Theranostics 2017, 7, 4618.

21. Boucher, M.; Geffroy, F.; Prévéral, S.; Bellanger, L.; Selingue, E.; Adryanczyk-Perrier, G.; Pean, M.; Lefèvre, C.; Pignol, D.; Ginet, N., Genetically Tailored Magnetosomes Used as MRI Probe for Molecular Imaging of Brain Tumor. Biomaterials 2017, 121, 167-178.

22. Roda, A.; Cevenini, L.; Borg, S.; Michelini, E.; Calabretta, M. M.; Schüler, D., Bioengineered Bioluminescent Magnetotactic Bacteria as a Powerful Tool for Chip-Based Whole-Cell Biosensors. Lab on a Chip 2013, 13, 4881-4889.

23. Alphandery, E.; Faure, S.; Seksek, O.; Guyot, F.; Chebbi, I., Chains of Magnetosomes Extracted from Amb-1 Magnetotactic Bacteria for Application in Alternative Magnetic Field Cancer Therapy. ACS Nano 2011, 5, 6279-6296.

24. Sangnier, A. P.; Preveral, S.; Curcio, A.; Silva, A. K.; Lefèvre, C. T.; Pignol, D.; Lalatonne, Y.; Wilhelm, C., Targeted Thermal Therapy with Genetically Engineered Magnetite Magnetosomes@ Rgd: Photothermia Is Far More Efficient Than Magnetic Hyperthermia. J. Control. Release 2018, 279, 271-281.

25. Chen, C.; Wang, S.; Li, L.; Wang, P.; Chen, C.; Sun, Z.; Song, T., Bacterial Magnetic Nanoparticles for Photothermal Therapy of Cancer under the Guidance of MRI. Biomaterials 2016, 104, 352-360.

26. Herborn, C.; Papanikolaou, N.; Reszka, R.; Grünberg, K.; Schüler, D.; Debatin, J., Magnetosomes as Biological Model for Iron Binding: Relaxivity Determination with MRI. ROFOFortschr. Rontg. 2003, 175, 830-834.

27. Xiang, Z.; Yang, X.; Xu, J.; Lai, W.; Wang, Z.; Hu, Z.; Tian, J.; Geng, L.; Fang, Q., Tumor Detection Using Magnetosome Nanoparticles Functionalized with a Newly Screened Egfr/Her2 Targeting Peptide. Biomaterials 2017, 115, 53-64.

28. Sun, J.; Tang, T.; Duan, J.; Xu, P.-x.; Wang, Z.; Zhang, Y.; Wu, L.; Li, Y., Biocompatibility of Bacterial Magnetosomes: Acute Toxicity, Immunotoxicity and Cytotoxicity. Nanotoxicology 2010, 4, 271-283.

29. Qi, L.; Lv, X.; Zhang, T.; Jia, P.; Yan, R.; Li, S.; Zou, R.; Xue, Y.; Dai, L., Cytotoxicity and Genotoxicity of Bacterial Magnetosomes against Human Retinal Pigment Epithelium Cells. Sci. Rep. 2016, 6, 26961.

30. Cypriano, J.; Werckmann, J.; Vargas, G.; dos Santos, A. L.; Silva, K. T.; Leao, P.; Almeida, F. P.; Bazylinski, D. A.; Farina, M.; Lins, U., Uptake and Persistence of Bacterial Magnetite Magnetosomes in a Mammalian Cell Line: Implications for Medical and Biotechnological Applications. PloS one 2019, 14, e0215657.

31. Guo, F. F.; Yang, W.; Jiang, W.; Geng, S.; Peng, T.; Li, J. L., Magnetosomes Eliminate Intracellular Reactive Oxygen Species in Magnetospirillum Gryphiswaldense Msr-1. Environ. Microbiol. 2012, 14, 1722-1729.

32. Li, K.; Chen, C.; Chen, C.; Wang, Y.; Wei, Z.; Pan, W.; Song, T., Magnetosomes Extracted from Magnetospirillum Magneticum Strain Amb-1 Showed Enhanced Peroxidase-Like Activity under Visible-Light Irradiation. Enzyme Microb. Technol. 2015, 72, 72-78.

33. Monteil, C. L.; Menguy, N.; Prévéral, S.; Warren, A.; Pignol, D.; Lefèvre, C. T., Accumulation and Dissolution of Magnetite Crystals in a Magnetically Responsive Ciliate. Appl. Environ. Microbiol. 84, e02865-17.

34. Liu, R.-t.; Liu, J.; Tong, J.-q.; Tang, T.; Kong, W.-C.; Wang, X.-w.; Li, Y.; Tang, J.-t., Heating Effect and Biocompatibility of Bacterial Magnetosomes as Potential Materials Used in Magnetic Fluid Hyperthermia. Prog. Nat. Sci. 2012, 22, 31-39.

35. Soldatov, M. A.; Göttlicher, J.; Kubrin, S. P.; Guda, A. A.; Lastovina, T. A.; Bugaev, A. L.; Rusalev, Y. V.; Soldatov, A. V.; Lamberti, C., Insight from X-Ray Absorption Spectroscopy to 
Octahedral/Tetrahedral Site Distribution in Sm-Doped Iron Oxide Magnetic Nanoparticles. J. Phys. Chem. C 2018, 122, 8543-8552.

36. Mazuel, F.; Espinosa, A.; Radtke, G.; Bugnet, M.; Neveu, S.; Lalatonne, Y.; Botton, G. A.; AbouHassan, A.; Wilhelm, C., Magneto-Thermal Metrics Can Mirror the Long-Term Intracellular Fate of Magneto-Plasmonic Nanohybrids and Reveal the Remarkable Shielding Effect of Gold. Adv. Funct. Mater. 2017, 27, 1605997.

37. Van de Walle, A.; Sangnier, A. P.; Abou-Hassan, A.; Curcio, A.; Hémadi, M.; Menguy, N.; Lalatonne, Y.; Luciani, N.; Wilhelm, C., Biosynthesis of Magnetic Nanoparticles from NanoDegradation Products Revealed in Human Stem Cells. Proc. Nat. Acad. Sc. USA 2019, 116, 4044-4053. 38. Jansen, E.; Kyek, A.; Schäfer, W.; Schwertmann, U., The Structure of Six-Line Ferrihydrite. Appl. Phys. A 2002, 74, s1004-s1006.

39. Sánchez-Marcos, J.; Laguna-Marco, M.; Martínez-Morillas, R.; Céspedes, E.; Menéndez, N.; Jiménez-Villacorta, F.; Prieto, C., X-Ray Absorption and Mössbauer Spectroscopies Characterization of Iron Nanoclusters Prepared by the Gas Aggregation Technique. J. Nanosci. Nanotech. 2012, 12, 86198623.

40. Marcano, L.; Munoz, D.; Martín-Rodríguez, R.; Orue, I.; Alonso, J.; García-Prieto, A.; Serrano, A.; Valencia, S.; Abrudan, R.; Fernández Barquín, L., Magnetic Study of Co-Doped Magnetosome Chains. J. Phys. Chem. C 2018, 122, 7541-7550.

41. Malferrari, D.; Castellini, E.; Bernini, F.; Rubio, A. S.; Castro, G. R.; Sainz-Díaz, C. I.; Caleffi, M.; Brigatti, M. F.; Borsari, M., Chemical Trapping of Gaseous H $2 \mathrm{~S}$ at High and Low Partial Pressures by an Iron Complex Immobilized inside the Montmorillonite Interlayer. Micropor. Mesopor. Mater. 2018, 265, 8-17.

42. Carta, D.; Casula, M. F.; Corrias, A.; Falqui, A.; Navarra, G.; Pinna, G., Structural and Magnetic Characterization of Synthetic Ferrihydrite Nanoparticles. Mater. Chem. Phys. 2009, 113, 349-355.

43. Espinosa, A.; Kolosnjaj-Tabi, J.; Abou-Hassan, A.; Plan Sangnier, A.; Curcio, A.; Silva, A. K.; Di Corato, R.; Neveu, S.; Pellegrino, T.; Liz-Marzán, L. M., Magnetic (Hyper) Thermia or Photothermia? Progressive Comparison of Iron Oxide and Gold Nanoparticles Heating in Water, in Cells, and In Vivo. Adv. Funct. Mater. 2018, 28, 1803660.

44. Rossi, A. L.; Longuinho, M. M.; Tanaka, M. N.; Farina, M.; Borojevic, R.; Rossi, A. M., Intracellular Pathway and Subsequent Transformation of Hydroxyapatite Nanoparticles in the Saos-2 Osteoblast Cell Line. J. Biomed. Mater. Res. Part A 2018, 106, 428-439.

45. Brem, F.; Hirt, A. M.; Winklhofer, M.; Frei, K.; Yonekawa, Y.; Wieser, H.-G.; Dobson, J., Magnetic Iron Compounds in the Human Brain: A Comparison of Tumour and Hippocampal Tissue. J. R. Soc. Interface 2006, 3, 833-841.

46. Kobayashi, A.; Yamamoto, N.; Kirschvink, J., Studies of Inorganic Crystals in Biological Tissue: Magnetite in Human Tumor. J. Jpn. Soc. Powd. Powd. Met. 1997, 44, 294-300.

47. Sant'Ovaia, H.; Marques, G.; Santos, A.; Gomes, C.; Rocha, A., Magnetic Susceptibility and Isothermal Remanent Magnetization in Human Tissues: A Study Case. Biometals 2015, 28, 951-958.

48. Baker, R. R.; Mather, J. G.; Kennaugh, J. H., Magnetic Bones in Human Sinuses. Nature 1983, 301,78 .

49. Murros, K. E.; Salminen, J.; Wasiljeff, J.; Macías-Sánchez, E.; Soinne, L. S.; Faivre, D.; Valtonen, J.; Pohja, M.; Saari, P.; Pesonen, L., Magnetic Nanoparticles in Human Cervical Skin. Front. Med. 2019, $6,123$.

50. Pankhurst, Q.; Hautot, D.; Khan, N.; Dobson, J., Increased Levels of Magnetic Iron Compounds in Alzheimer's Disease. J. Alzheimer's Dis. 2008, 13, 49-52.

51. Plascencia-Villa, G.; Ponce, A.; Collingwood, J. F.; Arellano-Jiménez, M. J.; Zhu, X.; Rogers, J. T.; Betancourt, I.; José-Yacamán, M.; Perry, G., High-Resolution Analytical Imaging and Electron Holography of Magnetite Particles in Amyloid Cores of Alzheimer's Disease. Sci. Rep. 2016, 6, 24873.

52. Telling, N. D.; Everett, J.; Collingwood, J. F.; Dobson, J.; van der Laan, G.; Gallagher, J. J.; Wang, J.; Hitchcock, A. P., Iron Biochemistry Is Correlated with Amyloid Plaque Morphology in an Established Mouse Model of Alzheimer's Disease. Cell Chem. Biol. 2017, 24, 1205-1215. 
53. Wang, C. X.; Hilburn, I. A.; Wu, D.-A.; Mizuhara, Y.; Cousté, C. P.; Abrahams, J. N.; Bernstein, S. E.; Matani, A.; Shimojo, S.; Kirschvink, J. L., Transduction of the Geomagnetic Field as Evidenced from Alpha-Band Activity in the Human Brain. Eneuro 2019, 6, 1-23.

54. Mériaux, S.; Boucher, M.; Marty, B.; Lalatonne, Y.; Prévéral, S.; Motte, L.; Lefèvre, C. T.;

Geffroy, F.; Lethimonnier, F.; Péan, M., Magnetosomes, Biogenic Magnetic Nanomaterials for Brain Molecular Imaging with 17.2 T MRI Scanner. Adv. Healthc. Mater. 2015, 4, 1076-1083.

55. Ravel, B.; Newville, M., Athena, Artemis, Hephaestus: Data Analysis for X-Ray Absorption Spectroscopy Using Ifeffit. J. Synchr. Rad. 2005, 12, 537-541. 